\title{
Study on application technology of pulsating heat pipe
}

\author{
Jianhong Liu ${ }^{1, *}$, Fumin Shang ${ }^{1,2}$, Kangzhe Yang $^{1}$, Chaoyue Liu ${ }^{1}$, Yong $\mathrm{Wu}^{1}$ \\ ${ }^{1}$ Changchun Institute of Technology, School of Energy and Power, Jilin, China \\ ${ }_{2}^{2}$ Jilin Engineering Research Center for Building Energy Supply and Indoor Environmental Control, Jilin, China
}

\begin{abstract}
Pulsating heat pipe(PHP) has many advantages, such as small volume, simple structure, low cost, good heat transfer performance, it have great potential in the application of refrigeration, aerospace, waste heat recovery and low - grade energy utilization. Based on the analysis of a large number of research results at home and abroad, the application status of pulsating heat pipe technology is summarized in this paper, which can provide scientific guidance for the design, operation and large-scale application of pulsating heat pipe.
\end{abstract}

\section{Introduction}

With the development of modern high-tech, the heat load per unit area of many thermal equipment is getting higher and higher, such as ultra-high power integrated circuits, high-temperature fuel cells for power generation, nuclear reactors, it is often necessary to miniaturize the cooling or heat exchange equipment. Because of the limitation of carrying limit and other factors, the traditional heat pipe miniaturization can not meet these requirements. As a new type of heat transfer device, pulsating heat pipe has great potential applications in thermal control technology and other cooling fields, with small size, high flexibility, low cost, high heat transfer performance.

In this paper, the application research status of pulsating heat pipe in low temperature waste heat recovery, solar energy utilization, electronic components cooling and other fields is summarized, which can provide scientific guidance for the design, operation and largescale application of pulsating heat pipe.

\section{Application technology of pulsating heat pipe}

\subsection{Application in low temperature waste heat recovery}

Because the pulsating heat pipe has the advantages of small volume, high flexibility, simple and compact structure, low cost and high heat transfer performance, the research and development of the low-temperature waste heat recovery device for pulsating heat pipe was carried out, it will play a positive role in promoting in the field of further energy-saving work.

Rttidech [1] applied closed-ended pulsating heat pipe to the air preheating system, the experimental results showed that the heat recovery efficiency increased obviously with the increase of the heating gas temperature at the evaporation section.

Suprattanakul [2] applied pulsating heat pipes with one-way valves to air-conditioning systems, which use the pulsating heat pipes to recover the cooling from the exhaust air and pre-cool the fresh air.

Xiahou Guo-wei [3] proposed a parallel grooved plate pulsating heat pipe with radial connection and studied its start-up and heat transfer for the air energy recovery.

In the year of 2010, Fumin Shang [4, 5] designed an exciting coupled pulsating heat pipe heat exchanger, as shown in figure 1 , the coupling pulsating heat pipe was composed of the main pulsating heat pipe and the Cooscillation pulsating heat pipe, which point-to-point (or face-to-face) contacted and the orthogonal distribution of the two tube bundles of the pulsating heat pipe, an optimal effect of enhanced heat transfer could been obtained by the two mutual incentive pulsating heat pipes.

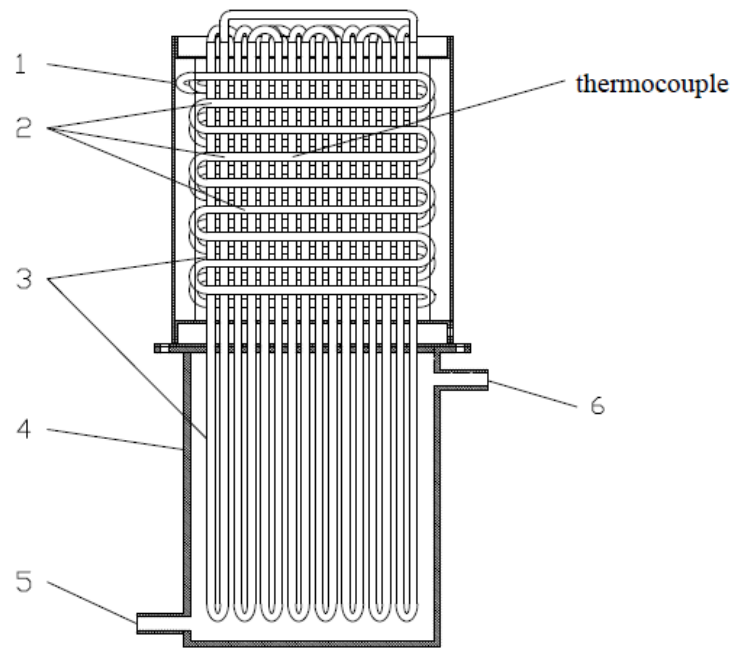

Fig.1 The pulsating heat pipes heat exchanger

In the year of 2016, Fumin Shang [6] designed the gasliquid pulsating heat pipe heat exchanger by combining the gas-liquid pulsating heat pipe with the fin, as shown in

\footnotetext{
*Corresponding author: liuljh@126.com
} 
figure 2, the whole heat transfer process of the heat exchanger is strengthened by the pulsating characteristics between the pulsating heat pipes and the fin structure, so it has the advantages of high heat recovery efficiency, simple structure and wide application range.

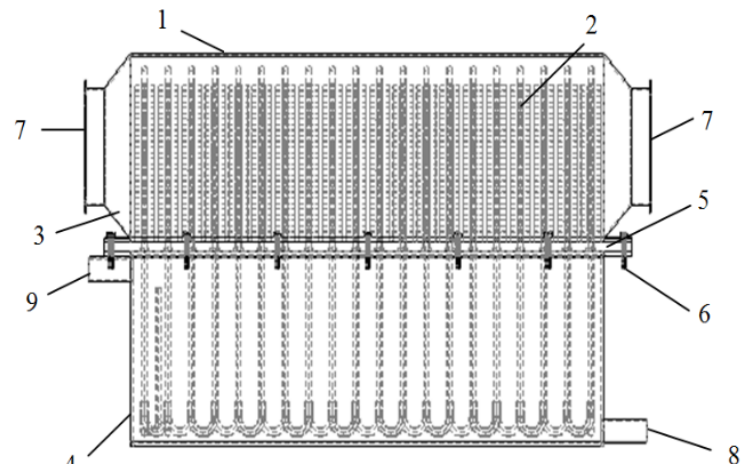

Fig.2 The gas-liquid pulsating heat pipe heat exchanger

\subsection{Application in solar energy utilization}

In the year of 2007 , Rittidech [7] designed a closed-end oscillating heat pipe solar collector, which had the same thermal efficiency as the traditional heat pipe solar collector, and had good anti-corrosion and anti-freezing performance in winter.

$\mathrm{Xu}$ [8] designed a new type of solar collector with pulsating heat pipe, the results showed that the efficiency of the system was greatly affected by the heat transfer performance of the pulsating heat pipe, and the heat resistance decreased with the increase of temperature.

Arab [9] built the evaporating section of a pulsating heat pipe into the solar water heating collector, the energy utilization efficiently was $53.79 \%$, compared with about $30 \%$ for conventional solar water heaters.

Nguyen [10] designed a solar collector with closedloop oscillating heat pipe and found that the efficiency could be further increased to $62 \%$.

Kargarsharifabad [11] installed the black heat collector on the evaporating section of the pulsating heat pipe to help absorb the solar energy, found that its energy efficiency increased to $66 \%$.

Fumin Shang $[12,13]$ used the pulsating heat pipe as a heat transfer element between solar energy and hot water (Air), and developed two kinds of solar energy collector with pulsating heat pipe.

Fig. 3 was the spiral pulsating heat pipe solar water heating device. To absorb solar energy better, the whole spiral pulsating heat pipe solar water heating is tilted at an angle to improve the heat collection effect.

Fig. 4 was the down-cooled pulsating heat pipe solar collector. The water tank was at the bottom and 12 groups of pulsating heat pipes were placed in the vacuum glass tubes. In this way, the efficiency of the solar energy collecting system was enhanced, and the antifreezing property of the solar energy collecting system is improved.

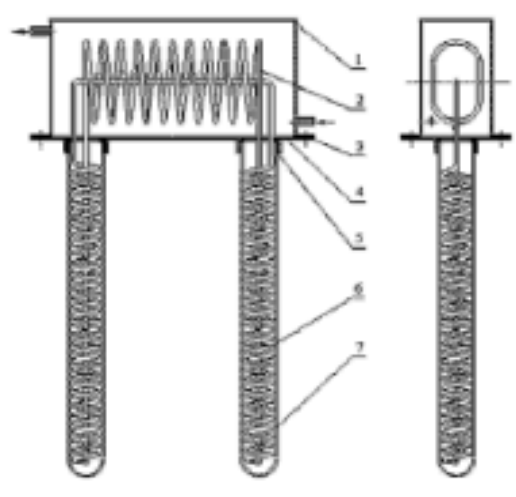

Fig.3 The spiral pulsating heat pipe solar water heating device

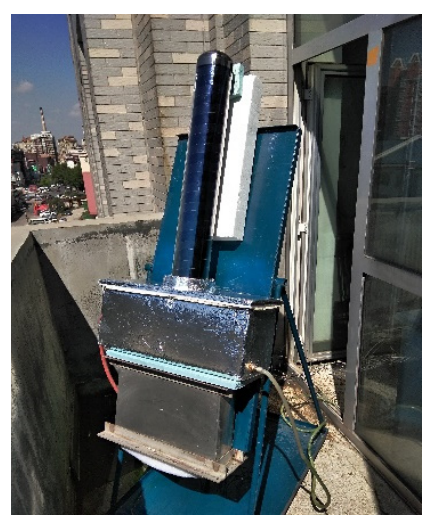

Fig.4 The Bottom-Cooling PHP in Solar Collector

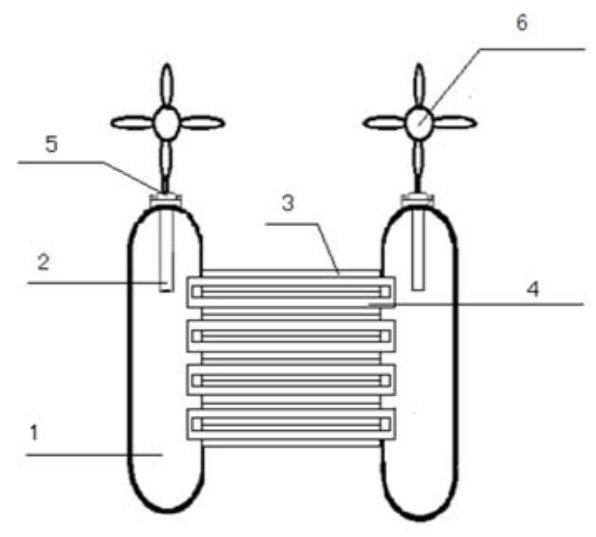

Fig.5 The new composite pulsating heat pipe solar water heater

Jianhong Liu [14] designed the pulsating heat pipe solar water heater, the advantages were simple overall structure and wide application range, and could effectively overcome the scaling, icing problems and the corrosion problems in the pipe Compared to the conventional solar water heater.

Jianhong Liu [15] showed the new composite pulsating heat pipe solar water heater, as shown in figure 5. The vacuum glass tube absorbed the solar energy and radiated heat to the heating section of the pulsating heat pipe, the working fluid in the pulsating heat pipe oscillates, pushing the working fluid to the condensing section of the pulsating heat pipe and heating the water in the water tank, thus realizing the heat transfer. 


\subsection{Application in the field of electronic components heat dissipation}

Pulsating heat pipe can be widely used as an efficient heat conduction element in the cooling field of electronic components. At present, there are a few pulsating heat pipe products mainly used in chip (CPU), insulated-gate bipolar transistor, High Power Integrated Circuit (LSI), diode, semiconductor thyratron and other electronic devices cooling. Due to the special structure of electronic devices, pulsating heat pipes can be machined into different structure types to suit the special requirements of installation space, as shown in figure 6. Also, it can be used as both a heat conducting substrate and a heat sink fin.

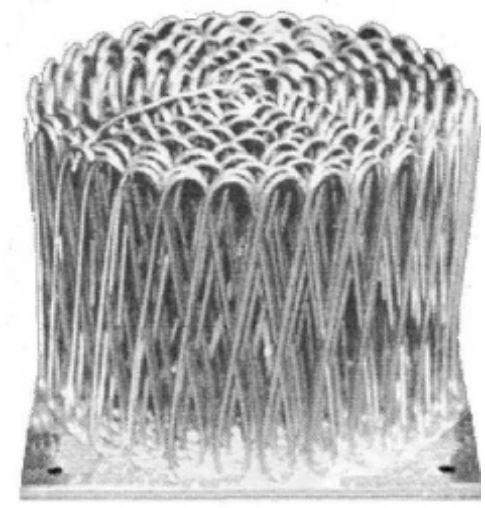

Fig.6 The Fin-type pulsating heat pipe radiator

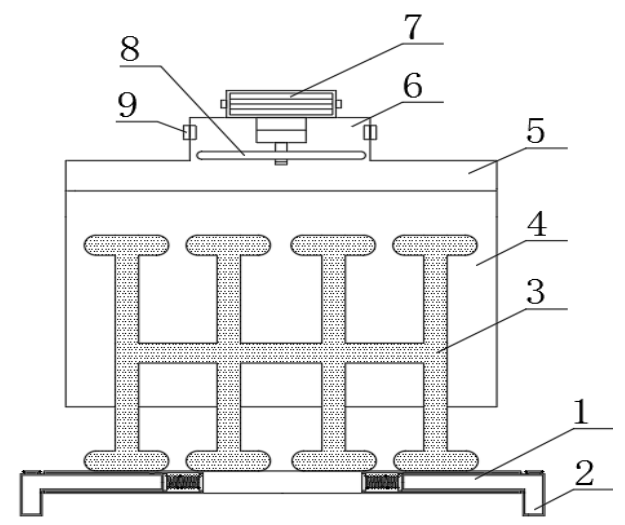

Fig.7 the connected pulsating heat pipe type electronic components heat dissipation device

Xiahou, Guowei et Al. [16] designed the vertically cooled CPU pulsating heat pipe radiator, the radiator had good stability and can effectively maintain the CPU temperature. Dang [17] designed the cooling system for the clearinghouse, with pulsating heat pipes as the main heat sink.

In 2019, Shang Fumin [18] designed the connected pulsating heat pipe type electronic components heat dissipation device, as shown in figure 7 , the experimental showed that the heat dissipation device had faster start-up speed and better heat transfer effect than the traditional pulsating heat pipe.

In 2011, Shang Fumin [19] processed the pulsating heat pipe into the radiator of the CPU of the computer. The results showed that when the pulsating heat pipe was started, the wall temperature of the heating device was generally lower than that of the pin-fin radiator.

\subsection{Application in solar energy utilization}

The pulsating heat pipe can be used in the cooling system of aviation, spacecraft, military and civil motor vehicles, because its working performance is less affected by vibration, acceleration and microgravity. In addition, the pulsating heat pipes have been reported in many fields, such as refrigeration [20], cell freezing [21] and superconducting magnet cooling [22] .

$\mathrm{Han} \mathrm{Xu}$ [23] designed the low temperature pulsating heat pipe using liquid nitrogen as working fluid. The results showed that the pulsating heat pipe had great potential in the field of low temperature biological preservation technology.

Clement [24] designed the pulsating heat pipe for cooling the Proton Exchange Membrane fuel cell. The results showed that the time of the pulsating heat pipe from start to steady operation is the shortest, and the temperature difference between evaporation section and condensation section is the smallest.

Thompson [25] used the plate-type structure to cool the electromagnetic launcher, and concluded that the plate-type pulsating heat pipe can meet the heat dissipation requirement of about $10 \mathrm{~kW}$ when combined with external active cooling method.

Manno [26] applied the plate pulsating heat pipe to the battery heat management system of the pure electric vehicle, and calculated the heat dissipation performance of the battery pack under different output power and tilt angle, the plate type pulsating heat pipe can keep the temperature of the battery within the working range.

\section{Conclusion and outlook}

Pulsating heat pipe has been paid more and more attention since it was put forward in 1990s. This paper focuses on the characteristics of pulsating heat pipe and its excellent heat transfer performance, the current application technology and the future development prospect in the fields of solar energy utilization, electronic component cooling, low temperature waste heat recovery, etc. With the pulsating heat pipe flow and heat transfer theory has been conquered, there will be more pulsating heat pipe technology products applied to the relevant fields.

\section{Acknowledgment}

This work was supported by the industrial technology research and development project of Jilin province (2019C057-5), the science and technology development project of Jilin province (Grant numbers 20190303113SF), and the 2019 Seed fund project of Changchun Institute of Technology (320190008). 


\section{References}

1. Rittidech S, Dangeton W, Soponronnarit S. Applied Energy, 82, 2 (2005)

2. SUPIRATTANAKUL P, RITTIDECH S , BUBPHACHOT B. Energy and Buildings, 43,(2011)

3. XIAHOU Guowei,XIE Mingfu, KONG Fangming, YANG Caiyun. Journal of Central South University, 1(2015)

4. An exciting coupled pulsating heat pipe heat exchanger, 201010192884.7(2011)

5. Coupled pulsating heat pipe heat exchanger, 201020216885.6(2011)

6. A gas-liquid pulsating heat pipe heat exchanger, 201620562228.4(2016)

7. Rittidech S, Wannapakne S. Applied Thermal Engineering, 27,12(2007)

8. Xu R J, Zhang X H, Wang R X, et al. Energy Conversion and Management, 148(2017)

9. Arab M, Soltanieh M, Shafii M B. Exp Therm Fluid Sci, 42, 6(2012)

10. Nguyen K B, Yoon S H, Choi J H. J Mech Sci Technol, 26, 1(2012)

11. Kargarsharifabad H, Mamouri S J, Shafii M B, et al. J R enewable Sustainable Energy, 5( 2013)

12. The spiral pulsating heat pipe solar water heating device, 201020172324.0(2010)

13. Shang Fumin, Dong Yifang, Fan Shilong, Yang Qingjing. Journal of Engineering for Thermal Energy and Power, 35, 3(2020)

14. The pulsating heat pipe solar water heater, 201621073170.3(2017)

15. The new composite pulsating heat pipe solar water heater, 201920017811.0(2019)

16. Xiahou G, Zhang J, Ma R, et al. International Journal of Heat and Mass Transfer, 130(2019)

17. Dang C, Jia L, Lu Q. Applied Thermal Engineering, 110,5(2017)

18. The connected pulsating heat pipe type electronic components heat dissipation device. 201910922067.3 (2004)

19. Fumin Shang, Qingjing Yang, Chaoyue Liu, Shilong Fan, Jianhong, Liu. CAES 2020

20. Yeunyongkul P, Sakulchangsatatai P. Kammuang-lue $\mathrm{N}$, et al. International 10th Heat Pipe Symposium(2011)

21. Jiao A J, Ma H B, Critser J K. International Journal of Heat and Mass Transfer, 56(2009) .

22. Natsume K, Mito T, Yanagi N, et al. Cryogenics, 51, 6(2010)

23. Han X, MaHB, Jiao AJ, et al. Cryobiology, 56, $3(2008)$

24. Clement J, Wang X. Applied Thermal Engineering, 50(2013)
25. Thompson $\mathrm{S} \mathrm{M}$, Tessler $\mathrm{B} \mathrm{S}, \mathrm{MaH}$, et a1. IEEE Transactions on Plasma Science, 41, 5(2013)

26. Manno V, Filippeschi S, Mameli M, et al. Interfacial Phenom Heat Transfer, 3, 4 (2015) 